\title{
eXtremeMAT: Preliminary Engineering Scale Simulations with a ROM Material
}

Stephanie A Pitts, Daniel Schwen, Benjamin W Spencer, Laurent Capolungo

December 2019

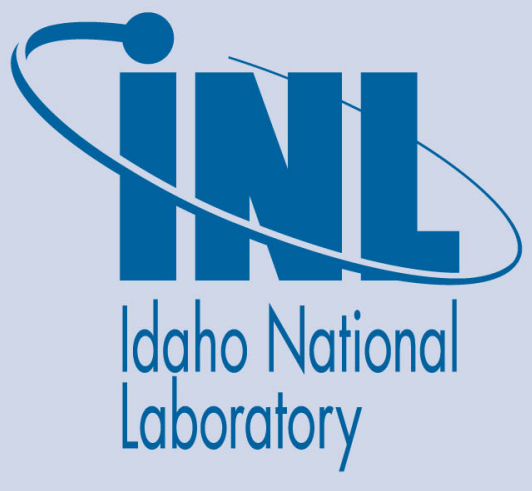

The INL is a U.S. Department of Energy National Laboratory operated by Battelle Energy Alliance

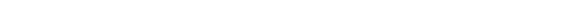




\section{eXtremeMAT: Preliminary Engineering Scale Simulations with a ROM Material}

Stephanie A Pitts, Daniel Schwen, Benjamin W Spencer, Laurent Capolungo

December 2019

Idaho National Laboratory Idaho Falls, Idaho 83415

http://www.inl.gov

Prepared for the U.S. Department of Energy

Office of Fossil Energy Under DOE Idaho Operations Office

Contract DE-AC07-05ID14517 


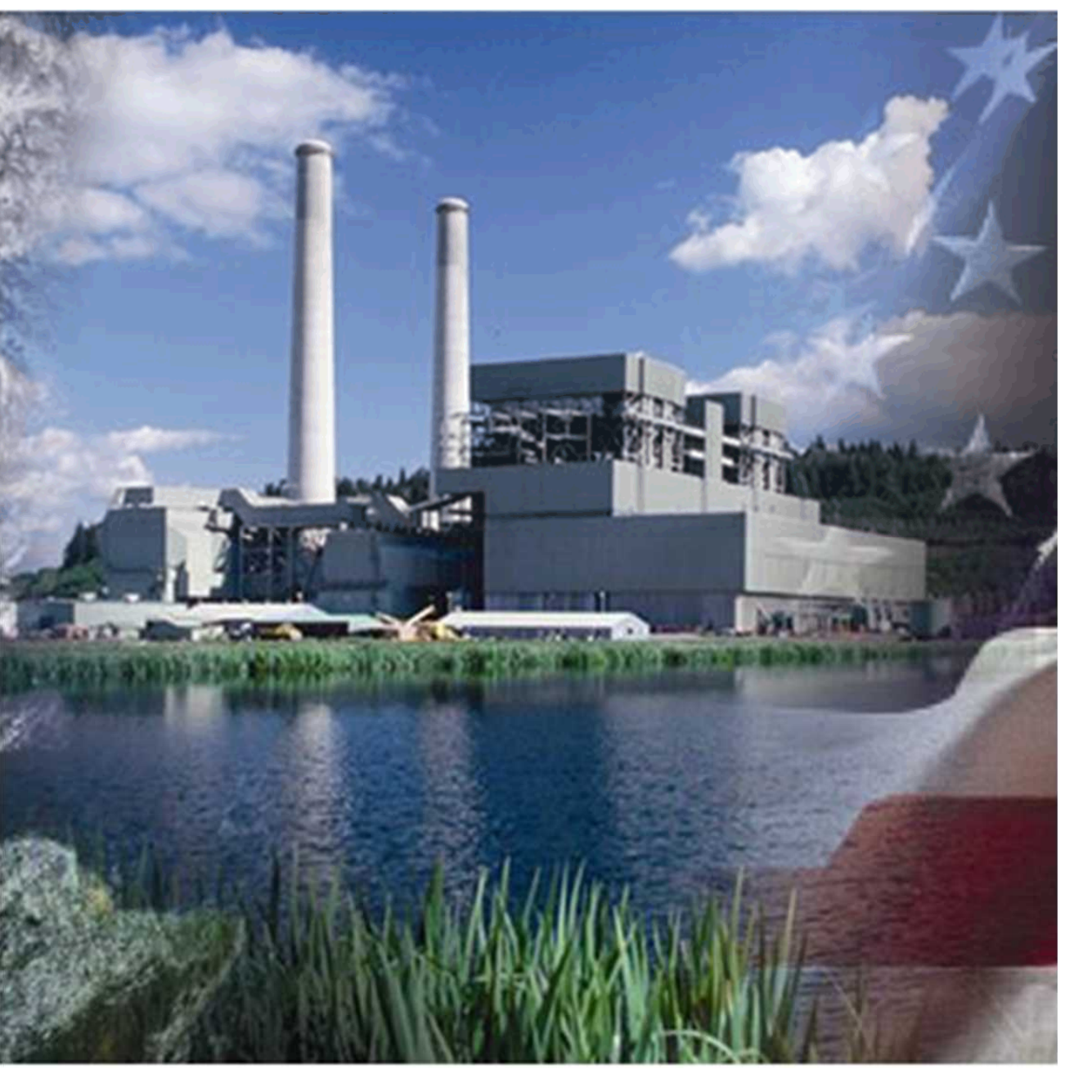

\title{
Preliminary Engineering Scale Simulations with a ROM Material
}

\author{
Stephanie Pitts, Daniel Schwen, Benjamin Spencer \\ Idaho National Laboratory
}




\section{Bottom Line Up Front}

Task 2.5 Objective: Engineering scale simulations on the component scale using models informed by the different physics involved in oxidation

- Multiphysics problem for which the MOOSE framework is well suited

- Long-term goal of coupling the different physics required to model oxidation within an engineering scale simulation

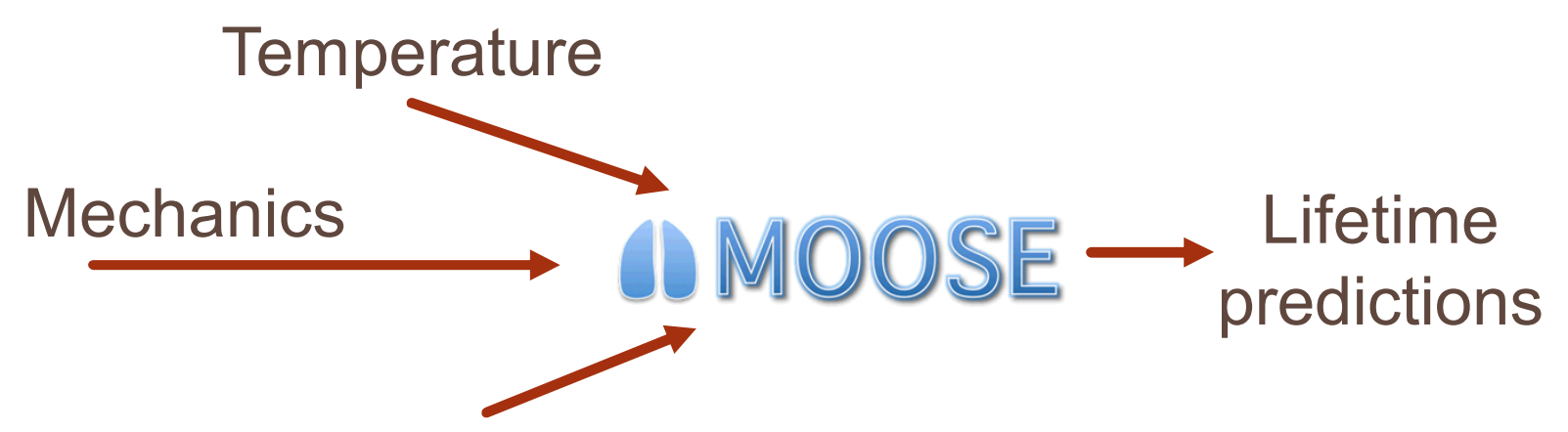

Oxide kinetics

- Preliminary work demonstrates the capability to solve mechanics simulations relevant to high temperature oxidation 


\section{Focus on Proof-of-Concept}

Emphasis on demonstrating the capability of MOOSE to model the oxidation problem with simplified problems on the engineering component scale:

- Pressurized capsule under uniaxial tension

- Oxidized plate with prescribe oxide growth
Goal to discuss how we can collaborate with the XMAT community to expand these preliminary modeling efforts:

- Brief overview of plans for next stage of engineering scale model and capability development 


\section{Pressurized Capsule}

Demonstrates the use of a reduced order model, originally developed at LANL based on VPSC simulations and implemented as a constitutive model in MOOSE, to model a simplified pressurized capsule with uniaxial tension

LAROMANCE model

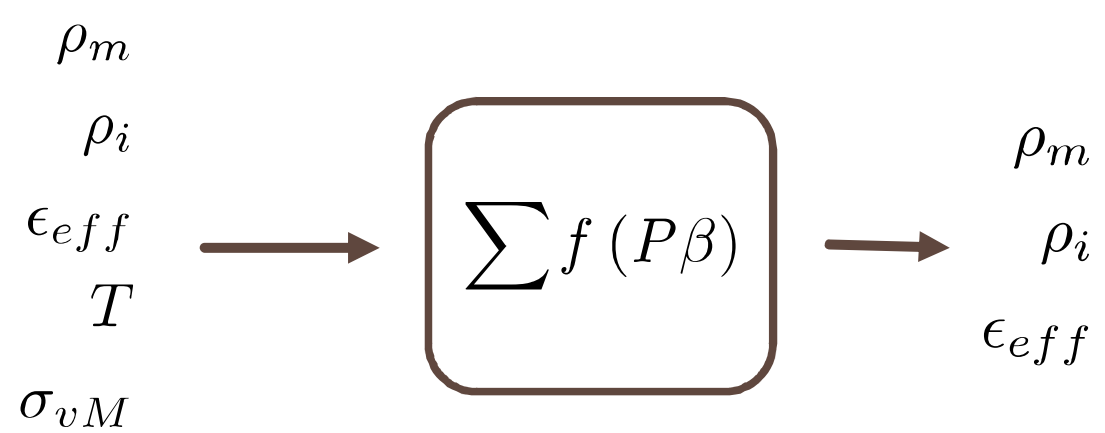

Calculates the effective plastic strain and dislocation densities from the previous stress, strain, dislocations, temperature state
MOOSE radial return algorithm

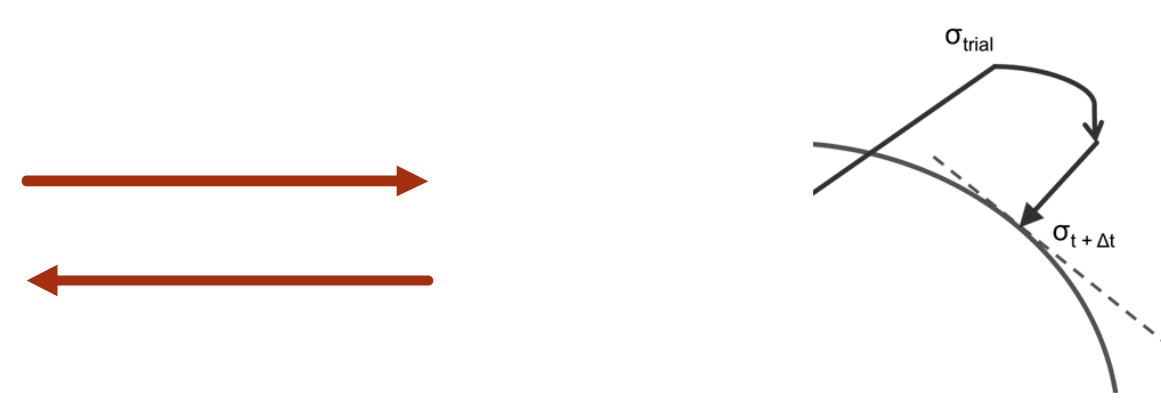

Iterates to return the stress state to the yield surface, using the LAROMANCE code as a constitutive model, to determine the required effective inelastic strain increment 
The 'Los Alamos Reduced Order Models for Advanced Nonlinear Constitutive Equations' model is a polynomial regression with a weighted sum of terms:

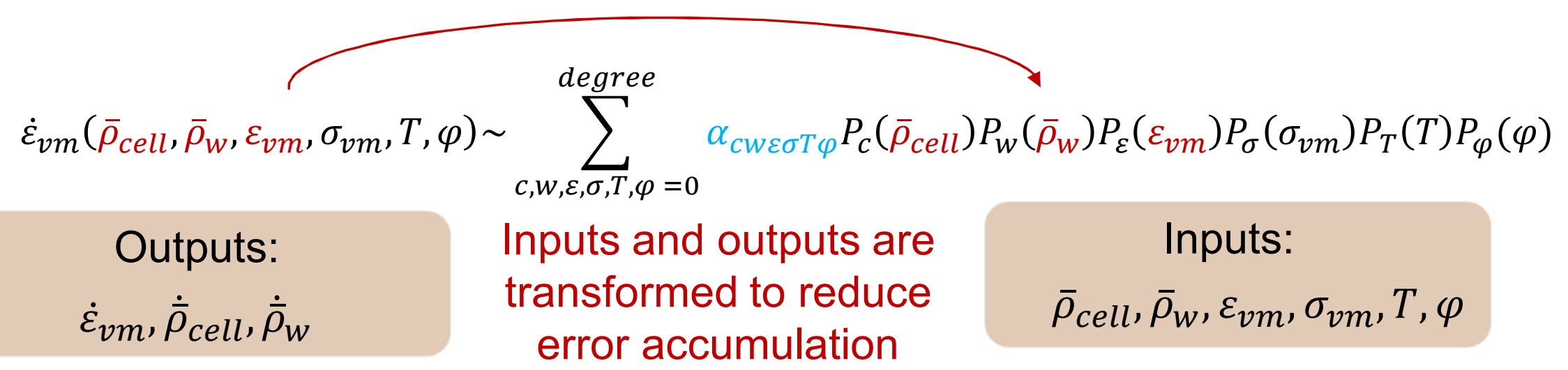

The coefficients capture the microstructural information that governs the strain response of the material and are material specific

- Fit $3 \times$ degree $^{6}$ coefficients

L. Capolungo 
Validated the LAROMANCE model against a VPSC simulation, comparing the predicted dislocation densities and strain

$$
\begin{aligned}
& \sigma_{v m}=\sqrt{3 J_{2}}=10.45 \mathrm{MPa} \\
& T_{0}=866.4 \mathrm{~K} \\
& \rho_{c e l l, 0}=7.951 \times 10^{12} \mathrm{~m}^{-2} \\
& \rho_{w, 0}=5.058 \times 10^{11} \mathrm{~m}^{-2}
\end{aligned}
$$
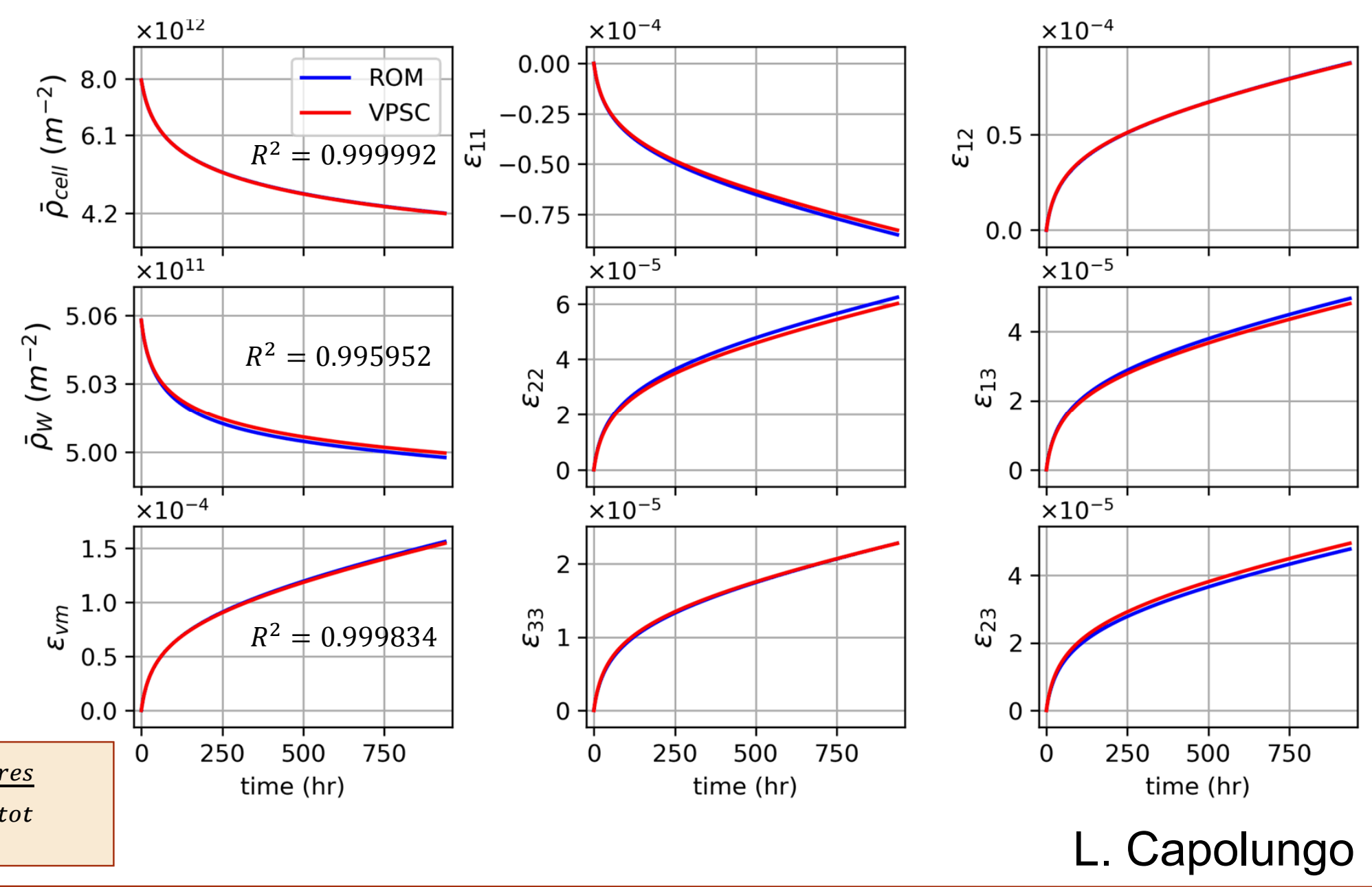

$R^{2}$ is measured for simulation of $\varepsilon_{v m}: R^{2}$
$S S_{t o t}=\sum\left(\varepsilon_{v m}^{V S S C}-\bar{\varepsilon}_{v m}^{V P S C}\right)^{2} ; S S_{r e s}=\sum\left(\varepsilon_{v m}^{R O M}-\varepsilon_{v m}^{V P S C}\right)^{2}$

Lawrence Livermore National Laboratory
- LOSA Alamos OAK RIDGE 
With the LAROMANCE constitutive model implemented in MOOSE, sampled the entire allowable input parameter space, evenly divided into six regions, to ensure the radial return implementation is reliable

\begin{tabular}{cccc} 
Temperature $(\mathrm{K})$ & Pressure $(\mathrm{MPa})$ & Mobile Disl $\left(\mathrm{m}^{-2}\right)$ & Immobile Disl $\left(\mathrm{m}^{-2}\right)$ \\
\hline 950 & 50.0 & $1.0 \mathrm{e} 13$ & $1.0 \mathrm{e} 12$ \\
910 & 40.9 & $9.0 \mathrm{e} 12$ & $8.6 \mathrm{e} 11$ \\
870 & 30.0 & $8.0 \mathrm{e} 12$ & $7.2 \mathrm{e} 11$ \\
830 & 20.0 & $7.0 \mathrm{e} 12$ & $5.8 \mathrm{e} 11$ \\
790 & 10.0 & $6.0 \mathrm{e} 12$ & $4.4 \mathrm{e} 11$ \\
750 & 2.0 & $5.0 \mathrm{e} 12$ & $3.0 \mathrm{e} 11$ \\
\hline
\end{tabular}

- Varied temperature and pressure individually while keeping mobile and immobile dislocations paired to simplify the parameter space

- Single Hex8 element, constant temperature and pressure 
With the LAROMANCE constitutive model implemented in MOOSE, sampled the entire allowable input parameter space, evenly divided into six regions

Initial Densities: $\rho_{m} 1.0 \mathrm{e} 13 \mathrm{~m}^{-2}$ and $\rho_{i} 1.0 \mathrm{e} 12 \mathrm{~m}^{-2}$

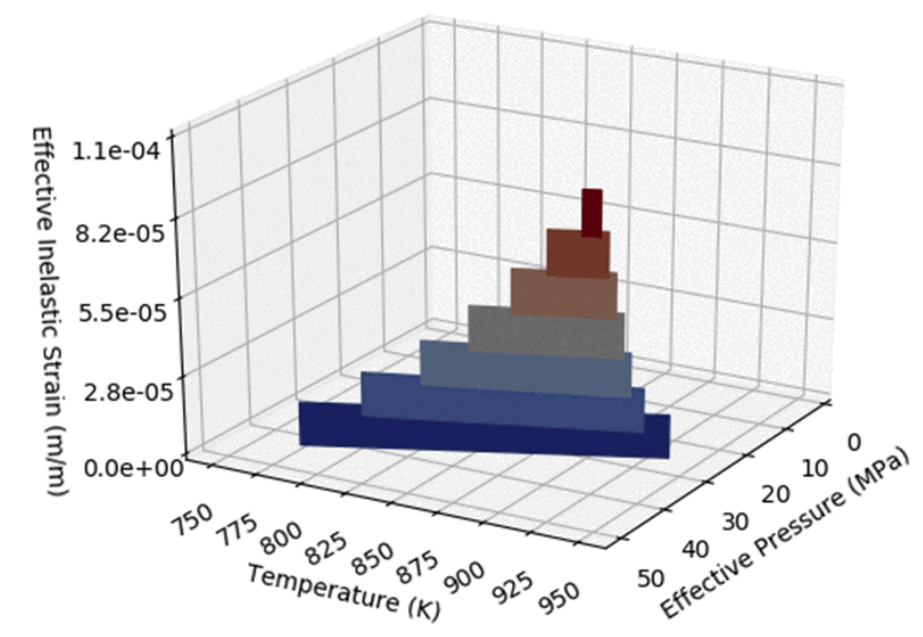

Higher effective strains calculated under in the higher temperature and pressure regions
Initial Densities: $\rho_{m} 1.0 \mathrm{e} 13 \mathrm{~m}^{-2}$ and $\rho_{i} 1.0 \mathrm{e} 12 \mathrm{~m}^{-2}$

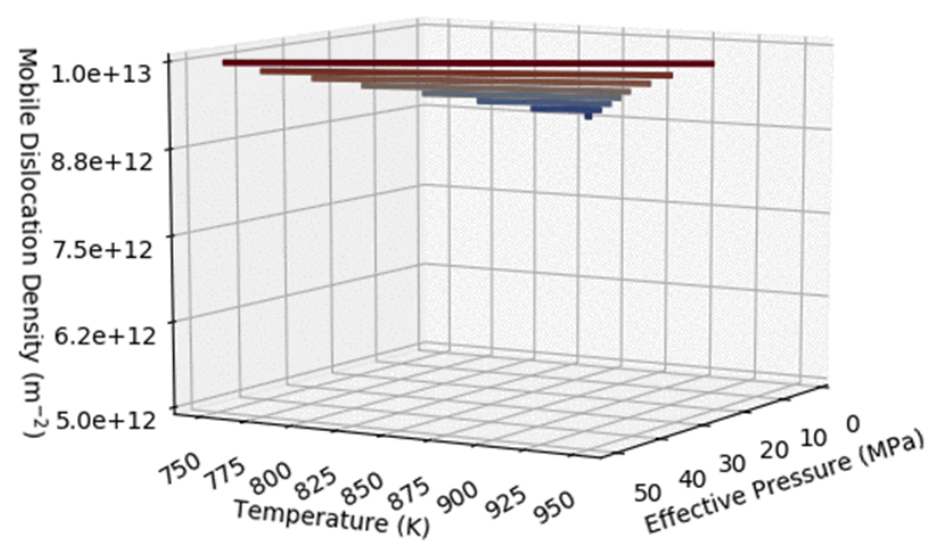

More mobile dislocations are retained in the lower temperatures and pressures (fewer drivers for dislocation annihilation) 


\section{Capsule Geometry and Model}

Use the LAROMANCE model in MOOSE for SS316H

- Developed for a previous cladding application

Use $1 / 8$ symmetry geometry

- $5 \mathrm{~cm}$ height, $2 \mathrm{~cm}$ radius, $0.2 \mathrm{~cm}$ thickness

- Apply internal pressure, uniaxial tension to outer cap

Allowable ranges limited:

- Effective stress: $2 \mathrm{MPa}-50 \mathrm{MPa}$

- Temperature: use $801^{\circ} \mathrm{C}$

Similar hoop and von Mises stress values with internal pressure only
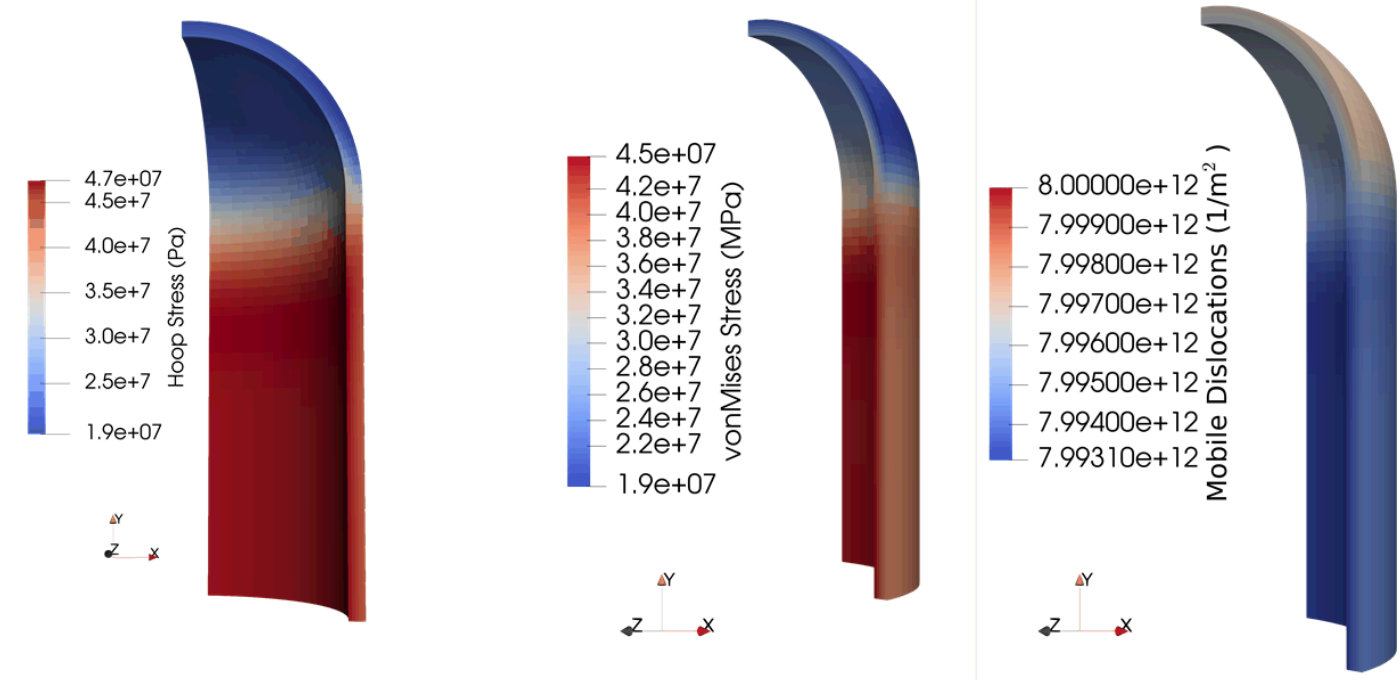


\section{Simplified Uniaxial Tension Cases}

- Different strain rates $(1.64 \mathrm{e}-8$ to $1.64 \mathrm{e}-5 \mathrm{~m} / \mathrm{s})$ to an approximate $0.01 \%$ strain with an internal pressure of 1.0 MPa (results shown for $1.64 \mathrm{e}-7 \mathrm{~m} / \mathrm{s}$ )

- Achievable hoop stress is limited by the higher effective von Mises stress
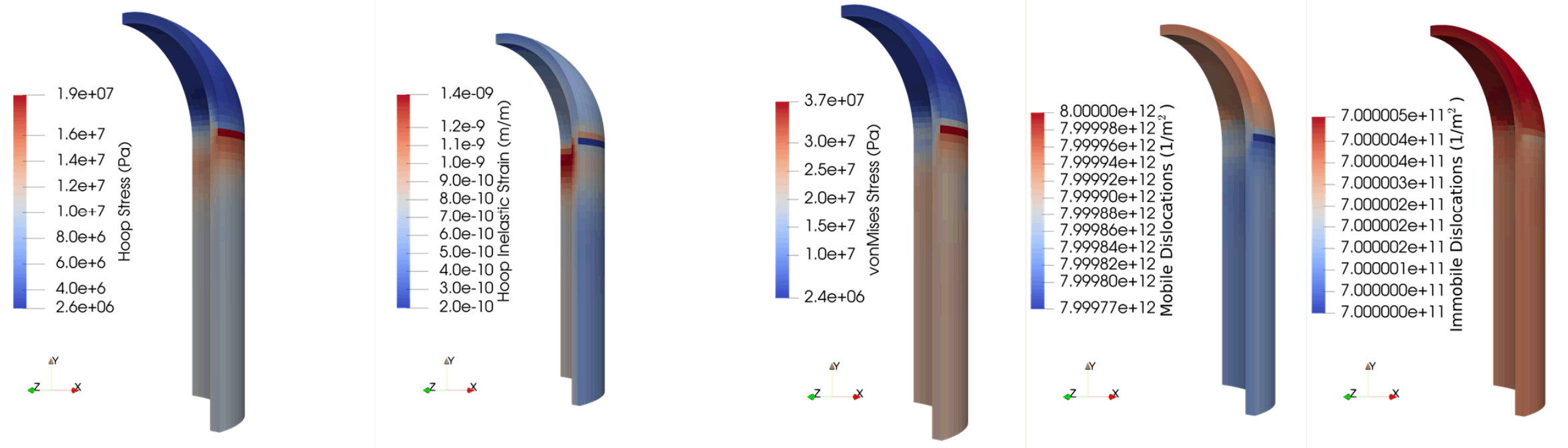

- The evolution of the inelastic hoop strain and dislocation densities is strongly dependent on the displacement rate used; these increase with lower strain rates 


\section{Investigate Impact of Static Hold}

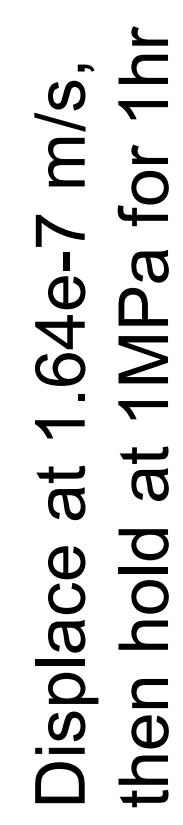
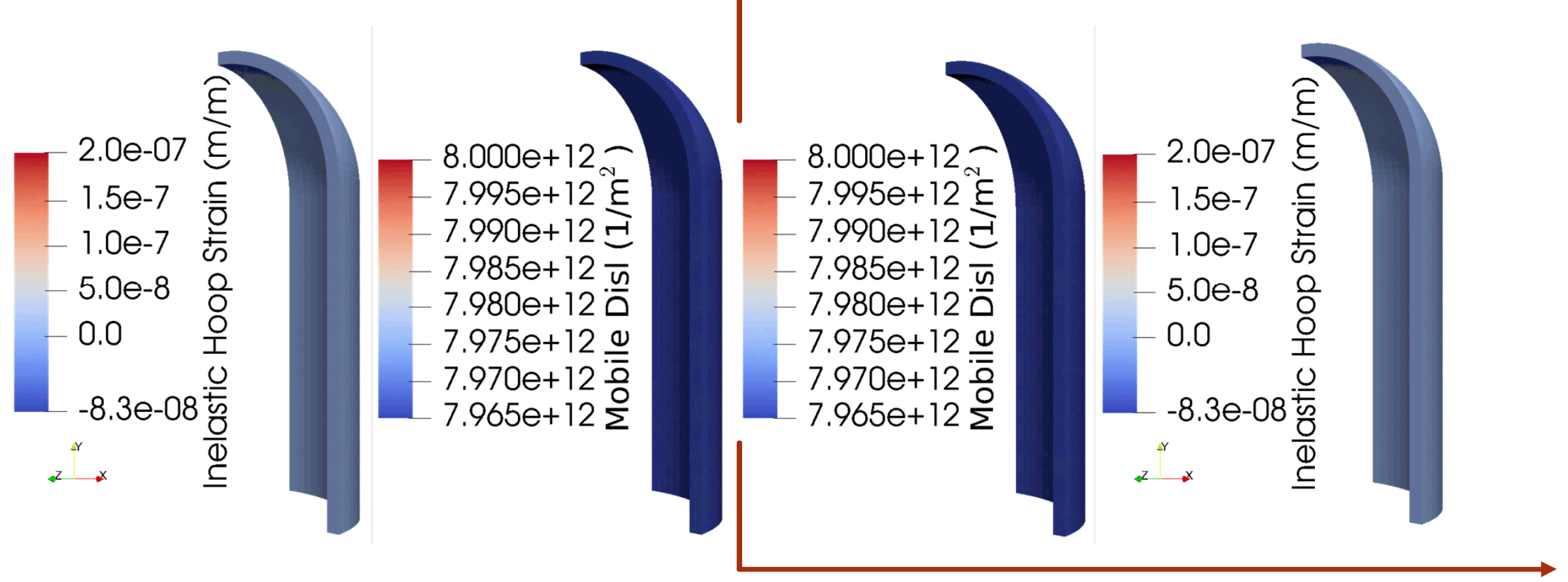

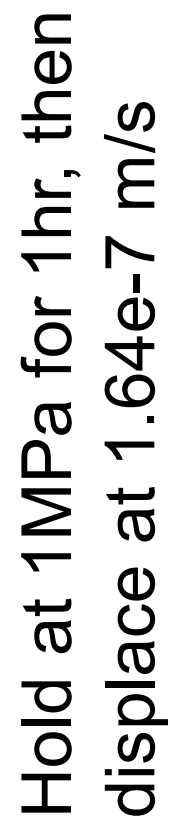

The variation in the inelastic strain and mobile dislocation responses, with equivalent final stress states, shows the importance of using a constitutive model capable of capturing strain history influence 


\section{Oxide Growth Induced Eigenstrain}

Demonstrate the mechanical response to an oxide growth induced eigenstrain with an engineering scale simulation as the oxide grows into the metal

- Focus on simulating the impact of the moving oxide interface on the mechanics

- Goal was to simulate both the oxide eigenstrain and the creep behavior

- Selected stainless steel $316 \mathrm{H}$ in order to use the LAROMANCE code

Assumptions for proof-of-concept:

- Stainless steel $316 \mathrm{H}$

- Thick beam of $0.1 \mathrm{~mm} \times 0.4 \mathrm{~mm}$, with pivot and fixed points along Prescribed growth rate the horizontal centerline

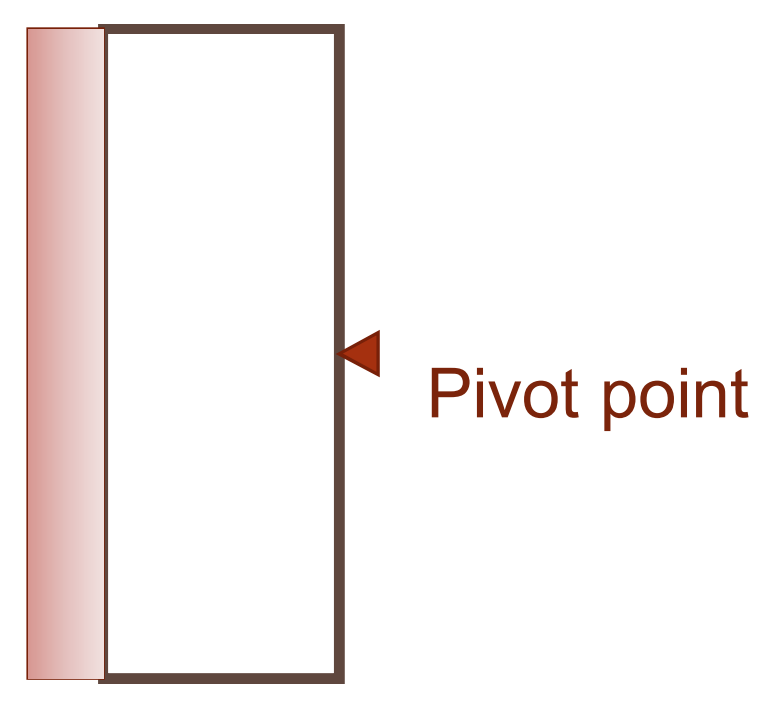


Focusing only on the mechanics simulation at this stage, prescribed an approximate oxide thickness growth rate for $\mathrm{SS} 316 \mathrm{H}$ at $801^{\circ} \mathrm{C}$

- Assume only external oxidation, no internal oxidation

- Chromia as sole, prefect, and dense oxide

- Fit equation for $k_{p}$ from mid-band for chromia formers (Gleeson 2010)

$$
x=\frac{6.93 \mathrm{~cm}^{3} / \mathrm{mol}}{1.5 \cdot 15.99 \mathrm{~g} / \mathrm{mol}} \cdot\left(k_{p} \cdot t\right)^{1 / 2} \quad k_{p}=3.26 \times 10^{-20} \times e^{0.0176 \times T}
$$

Apply a constant approximate volumetric eigenstrain to the oxide (Bernstein 1987)

$$
\epsilon_{i i}=\omega \cdot\left(\Phi^{1 / 3}-1\right)
$$




\section{Oxidized Plate Simulation}

Preliminary moving oxide interface model demonstrates expected stress patterns

Challenges in modeling required additional simplifications:

- Small, total strain formulation

- Isotropic elastic materials

- Diffuse interface approach requires mesh adaptivity
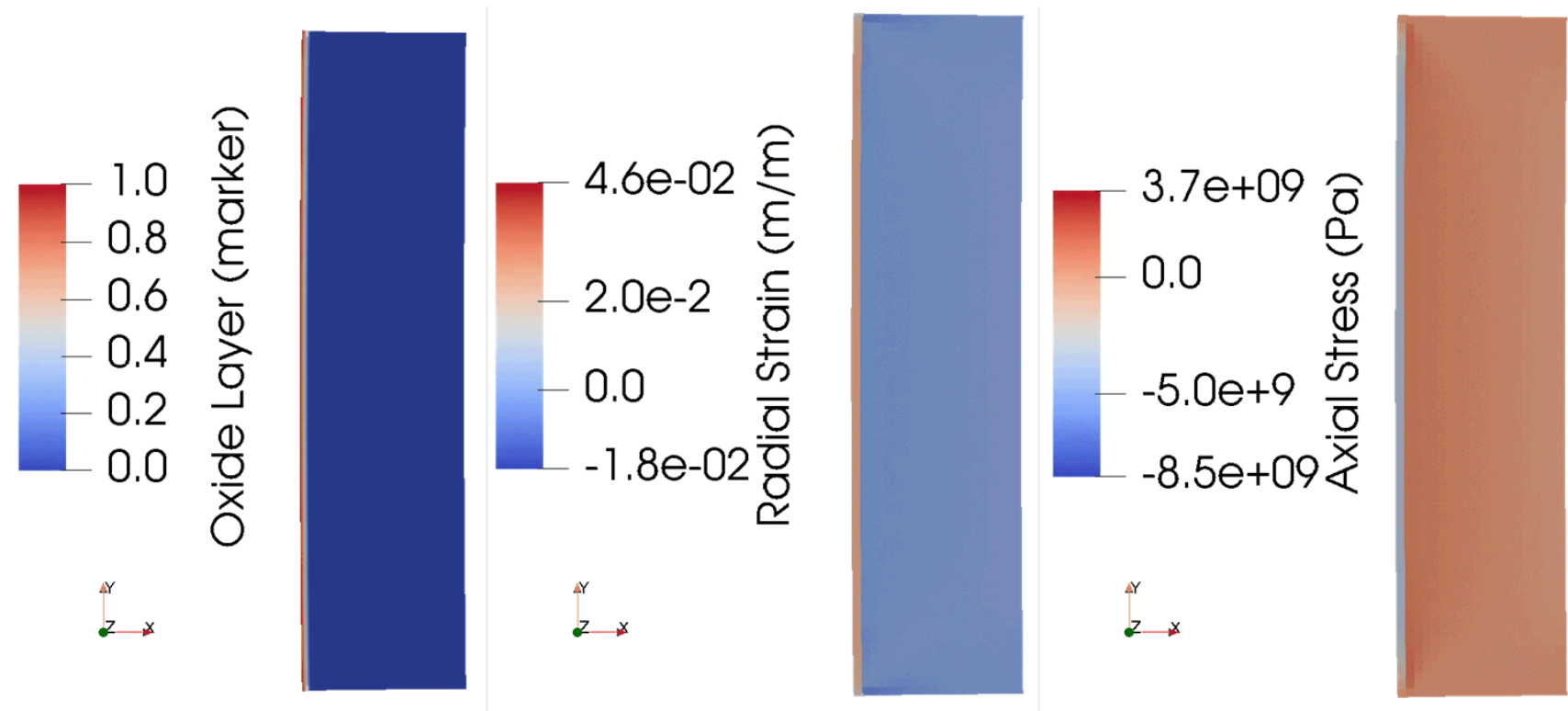

Continued development work required to address these challenges for mechanics simulation aspects of the oxidation modeling 
These preliminary simulations demonstrate MOOSE capabilities:

- Pressurized capsule simulation using the LAROMANCE code demonstrate the ability to capture the dependence of the material response on different loading histories

- Initial oxidized plate simulations highlight the need for continued mechanics capability development

These proof-of-concept modeling efforts provide a basis for future development within the XMAT framework:

- Collaboration on additional LAROMANCE code for SS347H

- Assistance with phase field modeling for oxide interface modeling 


\section{Explore Coupling with Phase Field}

Propose a multiscale simulation, using a set of phase field simulations to model the oxide layer growth and coupled to the mechanics
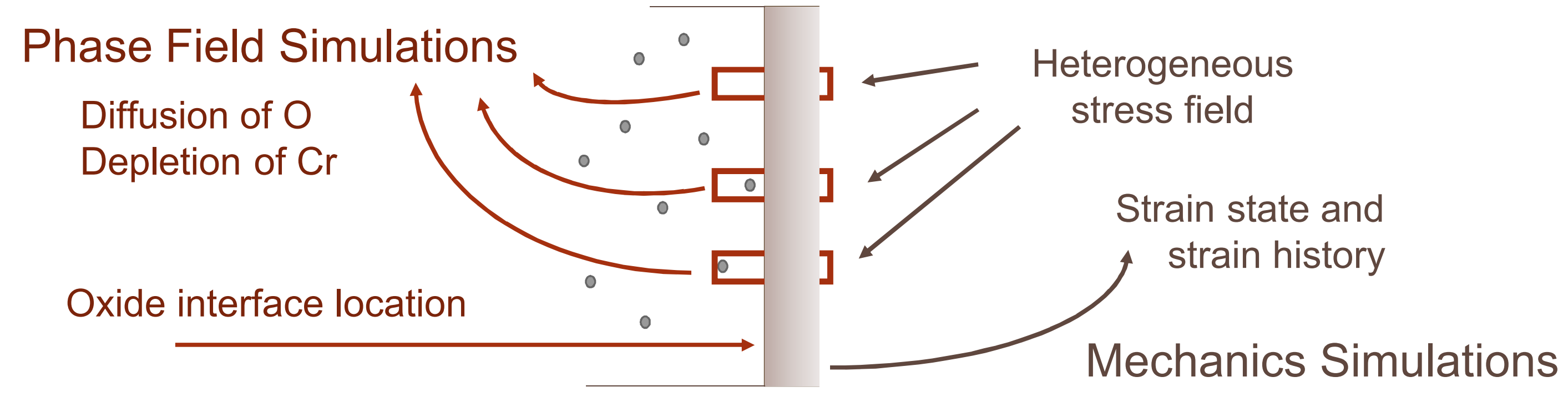

Hope to collaborate with Youhai Wen on phase field efforts to learn from and leverage the existing oxide kinetics modeling expertise in XMAT 


\section{Concurrent Modeling for Spallation}

Tight coupling with mechanics adds the capability to model damage, including cracking in the alloy and spallation of the oxide

- Given oxidation kinetics we can work towards predicting spallation

- Challenge: Passing the high tensile stresses in metal due to oxide growth induced strain to the oxidation kinetic model to account of additional pathways

Goal: Capture the influence of oxide growth and internal stress within the metal on the conditions that lead to spallation

- Challenges to address include:

- Predicting conditions that lead to cracking/buckling of the oxide (thermal expansion, microstructure)

- Accounting for the metal-oxide interface characteristics 


\section{Summary}

Task 2.5 Objective: Engineering scale simulations on the component scale using models informed by the lower-length scale physics involved in oxidation

- Preliminary proof-of-concept simulations to jump-start the engineering/component scale efforts using LAROMANCE codes

- Next steps involve coupling phase field simulations with mechanics to
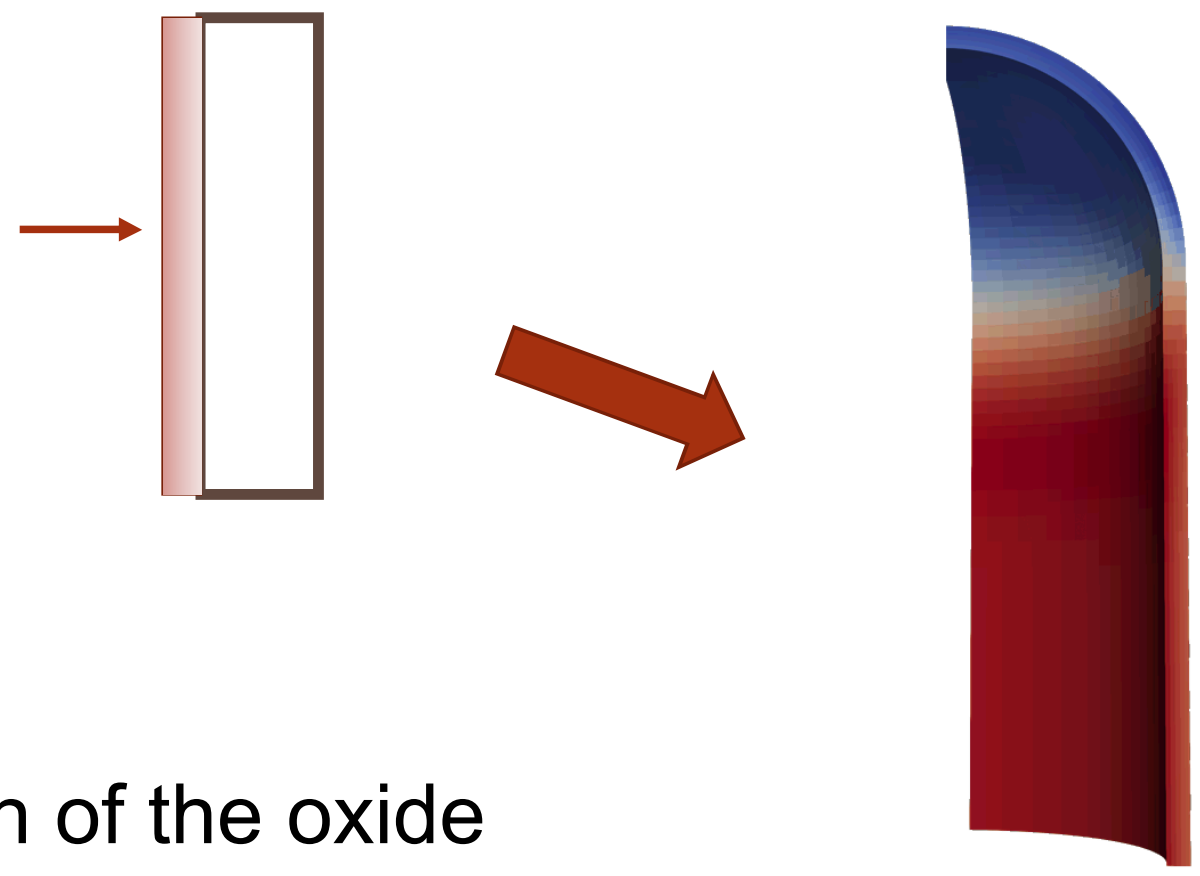
model the stress response to given oxide kinetics

- Focus on model predictions for spallation of the oxide 